\title{
Activity Pattern Mining from Social Media for Healthcare Monitoring on Big data
}

\author{
N.Priya, S. Sangeetha, S. Amudha
}

\begin{abstract}
Big data applications introduce novel openings for establishinginnovative information and produce differentadvanced methods to improve the worth of healthcare.In this paper, a novel activity pattern mining from social media for healthcare to examine big data applications in different biomedical multi-disciplines such as bioinformatics, medical imaging and community healthcare applications.Big data analytical tools perform the key part in their task for extracting hidden behavioural and expressive patterns frompersonal messages and their tweets. The behavioural patterns of the users can realizetheir additional informations about their concealed feelings and sentiments[1],[ 3],[5]. Further, the neural network is modelled to predict the psychological informations, such as nervousness, depression, behavioural disorder and mental stress.This is also shows that integrating variety of sources of data enables medical practitioner to show a novel investigation of patient care processes, improvements in new mobile healthcare technological developments aid real-time data collection, archiving and analysis of data in distributed environments.
\end{abstract}

Keywords : Healthcare, Big data, Activity Patterns

Likelihood.

\section{INTRODUCTION}

In recent biomedical and healthcare applications largely uses big data technology. Huge volumes of biological and medical images are collected and maintained in a speed and scalable environments. The technological improvements in parallel computing hardware and software's are drastically decreasing the difficulties in the field of pattern mining on biomedical data. Big data applications introduce recent openings for establishing recent information and produce new models to advance the worth of public healthcare. The activity pattern mining discussed in this paper examines big data applications applied in popularmulti-modal clinicalmulti-disciplines such as bioinformatics, medical imaging and community healthcare applications.

In particular, bioinformatics deals with improvement of throughput experiments that assist the investigation of novel genome-wide research studies of diseases. The medical

Revised Manuscript Received on July 22, 2019.

N.Priya, Department of CSE, Bharath Institute of Higher Education and Research, Chennai, India.Email: priyabiher@gmail.com

Ms. S. Sangeetha, Department of CSE, Bharath Institute of Higher Education and Research, Chennai, India.Email sangeethasathya01@gmail.com

Ms. S. Amudha, Department of CSE, Bharath Institute of Higher Education and Research, Chennai, Tamilnadu, India.Email: amudha17s@gmail.com imaging field aidsby large volume of clinical imaging data for creation of smartchoices. Now a day, the clinical imaging applications are greatly integrated with cloud environments forincreasing the availability of clinical images and public healthcare data for predicting and monitoring infectious disease outbreaks.

Wearable medical components with sensors are always produce huge data which is combined byformatted and unformatted data. If the data representation is complex, then, it is hard to manipulate and assess the big data for discovering important facts, which is helpful in making decisions. Hence, the data safetyhas the main constraint for clinical big data model.

\section{RELATED WORK}

The construction of IoT to store and manipulate scalable sensor information is proposed by GunasekaranManogaran et al., a novel architecture for healthcare applications. The architecture is implemented using low level modules such as, Meta Fog-Redirection (MF-R) and Grouping and Choosing (GC). The MF-R design exploits big data applicationsnamely, Apache Pig and Apache HBase for gathering and storing healthcare information data obtained from various sensor devices.

The presented GC design has been employed for safeguarding combination of fog through cloud computing [2 ],[ 4],[6].Moreoverthe design utilizes key management service and data classification operation like complex, dangerous and regular for providing safety provisions. Furthermore, this model utilizes MapReduce based prediction framework for predicting the heart related diseases.

YichuanWang, LeeAnn Kung and Terry Anthony Byrd et al. presented to examine the ancientadvancement, design frameworks and module utilities of big data analysis. The medical field is not entirelyclutched the possibleaids to be obtained from big data technologies. The constant improvement body of educationinvestigation on big data analysis is typically technology oriented. The importance of the big data technologies to be identified and investigations are immediately needed.

The aim is to identify various big data analysis abilities such as logical capability for deriving interesting patterns, unstructured data analysis ability, ability to support decision making process, predictive analysis and traceability. The benefits of big data analysis with respect to biomedical technology concernmapped operational, 
managerial and deliberatedomains. Further, it recommends various strategies for medical and clinical organizations, which are adopting big data technologies [7],[ 9], [11]

Abdulsalamet al., propose the framework that uses the smart household big data technology by studying and realizing novel activity patterns of public for community healthcare. The pattern and cluster analysis, and prediction are to calculate and analyze energy utilizationvariations in the human behaviour. Since, the habits of human are mainly recognized by their regular routines [8],[10],[12].Finding these routines allows predicting their activities. This paper deal with analyzingtime-based energy consumption patterns by application level that is straight associated to publicactions[13], [15],[17].

\section{BIG DATA ANALYTICS IN HEALTHCARE}

\section{A. Clinical Informatics}

Clinical informatics mainly deals with clinical imaging technology in the field of healthcare applications. It covers activity-based investigation, patient main diagnosis (MD)and cause of death (UCD)analysis, and processing of data obtained from EHRs and various sources like Electroencephalography (EEG), Computerised Tomography (CT), Magnetic Resonance Imaging (MRI), etc.

Here, the big data technologies/tools classified into different areas, such as different way of representations of data in organized saving and retrieval, interactive data processing[14],[ 16], [18].It pays high interest to data sharing and security related challenges. The image analysis is differing from bioinformatics and clinical informatics deals with organizing the data that develops specific ontologies.

\section{B. Imaging Informatics Applications}

Imaging informatics developed almost concurrentlythrough the EHRs and development of medical informatics. Though, it is differ from medical informatics owing to availability of heterogeneous types of imaging data derived from different modalities of clinical image dataset[19],[21],[23]. The data security is still an important concern in the domain, because recent models mainly rely on public cloud platforms and existing protocols.

\section{Bioinformatics applications}

Bioinformatics is an important research direction foranalyzing biological difference in the molecular level. These are an increasing requirement to develop, represent and analyze various datasets in time and it should be scalable to current trends in personalized medicine[20],[22], [24]. The part of big data tools in medical informatics technologies are data repositories, processing resources and novel data processing tools for collecting and analyzing biological data.

\section{Public Health Investigations}

The public health has various processes such as assessment, policy development and assurance. Assessment mainly involves gathering and investigating data to follow and examine community health position, thus supplying proof for selecting choices and policy preparations[25],[27],[29]. Assurance deals with validate the services provided by health organizations for increasing public health results. Public health investigation focuses on the following domains such as infectious disease surveillance, public health, mental health and chronic disease management.

\section{E. Surveillanceof Infectious disease}

Hay et al. proposed big data for universalcommunicable disease monitoring[26],[28],[30].They designed a framework offers real-time risk observing on map that directs machine learning and crowd sourcing. It results have opened new open doors for building up a refreshed map book for infection checking and thought about that online internet based life joined with epidemiological data is a vital novel information hotspot for encouraging general wellbeing observation.This is mainly used for social media disease monitoring, which is revealed between HIV-related tweets and frequency analysis.

\section{F. Population health monitoring}

The population health monitoring is deals with dissemination and impact of socio-demographic public related illness[31],[33],[35]. The outcomes reveal that the large-scale big data analysis is employed to efficiently analyze association of clinical image datasets.

\section{G. Mental health management}

The research relationship between miserable disorders and repeated thoughts/ruminating behaviour is assessed by Nambisan et al. and revealed that the messages placed in social media is employed to monitor and possibly sense depression. Big data analytical tools perform the key part in their task for extracting hidden behavioural and emotional patterns in informations and tweets[32],[34],[36]. The behavioural patterns of the social media users can realizemany things about their hidden emotions and sentiments. Further, the neural network used activity pattern mining can able to predict the psychological conditions of the social media users, such as nervousness, depression, behavioural disorder and mental stress.

\section{H. Chronic disease management}

The Cardiac Health monitoring in Ambulance Careunit is a distinctivecommunity based observational research plan intendedfor estimating and improving cardiovascular health and the superiority of ambulatory cardiac care. The studymotivated on findingchances to advance the key prevention of cardiacarrests. It uses the big data available at multiple distributed databases, such as electronic reviews, healthinessmonitoring, clinical lab, drug and clinical image datasets. The clinical data represented in the EHRs have been consolidated within specific datasets, while unstructured script informations, such as clinician notes are assessed and conceptualised for centralized access.

\section{CONCLUSION}

The Big data analysis is being quickly functional to biomedical and healthcare domains. The big data technology has provided an essentialpart in assessing and monitoring healthcare applications. In this review, various examples have been revealed in to understand the importance of big data technology in human healthcare investigations [37],[39],[41]. The recent development of the big data analysis domain are data integration, representation, data storing and indexing for retrieval, error detection, data security, contributionand investigation for patient e-records, publicrelated pages and integrated healthcare datasets. This is also shows that integrating variety of sources of data enables medical 
practitioner to show a novel investigation of patient care processes, availability of new mobile healthcaredevelopments aid real-time data gathering[38],[40].The distributed platform aids data archiving and analysis and presence of geographic and ecological information will further improves the ability to understand collected data and mining novel patterns.

\section{REFERENCES}

[1] Kumaravel A., Rangarajan K.,Algorithm for automaton specification for exploring dynamic labyrinths,Indian Journal of Science and Technology,V-6,I-SUPPL5,PP-4554-4559,Y-2013

[2] P. Kavitha, S. Prabakaran "A Novel Hybrid Segmentation Method with Particle Swarm Optimization and Fuzzy C-Mean Based On Partitioning the Image for Detecting Lung Cancer" International Journal of Engineering and Advanced Technology (IJEAT) ISSN: 2249-8958, Volume-8 Issue-5, June 2019

[3] Kumaravel A., Meetei O.N.,An application of non-uniform cellular automata for efficient cryptography,2013 IEEE Conference on Information and Communication Technologies, ICT 2013,V-,I-,PP-1200-1205,Y-2013

[4] Kumarave A., Rangarajan K.,Routing alogrithm over semi-regular tessellations,2013 IEEE Conference on Information and Communication Technologies, ICT 2013,V-,I-,PP-1180-1184,Y-2013

[5] P. Kavitha, S. Prabakaran "Designing a Feature Vector for Statistical Texture Analysis of Brain Tumor" International Journal of Engineering and Advanced Technology (IJEAT) ISSN: 2249-8958, Volume-8 Issue-5, June 2019

[6] Dutta P., Kumaravel A.,A novel approach to trust based identification of leaders in social networks,Indian Journal of Science and Technology,V-9,I-10,PP--,Y-2016

[7] Kumaravel A., Dutta P.,Application of Pca for context selection for collaborative filtering,Middle - East Journal of Scientific Research,V-20,I-1,PP-88-93,Y-2014

[8] Kumaravel A., Rangarajan K.,Constructing an automaton for exploring dynamic labyrinths,2012 International Conference on Radar, Communication and Computing, ICRCC 2012,V-,I-,PP-161-165,Y-2012

[9] P. Kavitha, S. Prabakaran "Adaptive Bilateral Filter for Multi-Resolution in Brain Tumor Recognition" International Journal of Innovative Technology and Exploring Engineering (IJITEE) ISSN: 2278-3075, Volume-8 Issue-8 June, 2019

[10] Kumaravel A.,Comparison of two multi-classification approaches for detecting network attacks, World Applied Sciences Journal,V-27,I-11,PP-1461-1465,Y-2013

[11]Tariq J., Kumaravel A.,Construction of cellular automata over hexagonal and triangular tessellations for path planning of multi-robots, 2016 IEEE International Conference on Computational Intelligence and Computing Research, ICCIC 2016,V-,I-,PP--,Y-2017

[12] Sudha M., Kumaravel A.,Analysis and measurement of wave guides using poisson method,Indonesian Journal of Electrical Engineering and Computer Science, V-8,I-2,PP-546-548,Y-2017

[13] Ayyappan G., Nalini C., Kumaravel A.,Various approaches of knowledge transfer in academic social network,International Journal of Engineering and Technology,V-,I-,PP-2791-2794,Y-2017

[14] Kaliyamurthie, K.P., Sivaraman, K., Ramesh, S. Imposing patient data privacy in wireless medical sensor networks through homomorphic cryptosystems 2016, Journal of Chemical and Pharmaceutical Sciences92.

[15] Kaliyamurthie, K.P., Balasubramanian, P.C. An approach to multi secure to historical malformed documents using integer ripple transfiguration 2016 Journal of Chemical and Pharmaceutical Sciences92.

[16]A.Sangeetha,C.Nalini,"Semantic Ranking based on keywords extractions in the web", International Journal of Engineering \& Technology, 7 (2.6) (2018) 290-292

[17] S.V.GayathiriDevi,C.Nalini,N.Kumar,"An efficient software verification using multi-layered software verification tool "International Journal of Engineering \& Technology, 7(2.21)2018 454-457

[18]C.Nalini,ShwtambariKharabe,"A Comparative Study On Different Techniques Used For Finger - Vein Authentication”, International Journal Of Pure And Applied Mathematics, Volume 116 No. 8 2017, 327-333, Issn: 1314-3395

[19] M.S. Vivekanandan and Dr. C. Rajabhushanam, "Enabling Privacy Protection and Content Assurance in Geo-Social Networks", International Journal of Innovative Research in Management, Engineering and Technology, Vol 3, Issue 4, pp. 49-55, April 2018.

[20]Dr. C. Rajabhushanam, V. Karthik, and G. Vivek, "Elasticity in Cloud Computing", International Journal of Innovative Research in Management, Engineering and Technology, Vol 3, Issue 4, pp. 104-111, April 2018.

[21]K. Rangaswamy and Dr. C. Rajabhushanamc, "CCN-Based Congestion Control Mechanism In Dynamic Networks", International Journal of Innovative Research in Management, Engineering and Technology, Vol 3, Issue 4, pp. 117-119, April 2018.

[22] Kavitha, R., Nedunchelian, R., "Domain-specific Search engine optimization using healthcare ontology and a neural network backpropagation approach", 2017, Research Journal of Biotechnology, Special Issue 2:157-166

[23] Kavitha, G., Kavitha, R., "An analysis to improve throughput of high-power hubs in mobile ad hoc network" , 2016, Journal of Chemical and Pharmaceutical Sciences, Vol-9, Issue-2: 361-363

[24] Kavitha, G., Kavitha, R., "Dipping interference to supplement throughput in MANET" , 2016, Journal of Chemical and Pharmaceutical Sciences, Vol-9, Issue-2: 357-360

[25] Michael, G., Chandrasekar, A.,'Leader election based malicious detection and response system in MANET using mechanism design approach", Journal of Chemical and Pharmaceutical Sciences(JCPS) Volume 9 Issue 2, April - June 2016.

[26]Michael, G., Chandrasekar, A.,'Modeling of detection of camouflaging worm using epidemic dynamic model and power spectral density", Journal of Chemical and Pharmaceutical Sciences(JCPS) Volume 9 Issue 2, April - June 2016.

[27] Pothumani, S., Sriram, M., Sridhar, J., Arul Selvan, G., Secure mobile agents communication on intranet,Journal of Chemical and Pharmaceutical Sciences, volume 9, Issue 3, Pg No S32-S35, 2016

[28]Pothumani, S., Sriram, M., Sridhar , Various schemes for database encryption-a survey, Journal of Chemical and Pharmaceutical Sciences, volume 9, Issue 3, Pg NoS103-S106, 2016

[29] Pothumani, S., Sriram, M., Sridhar, A novel economic framework for cloud and grid computing, Journal of Chemical and Pharmaceutical Sciences, volume 9, Issue 3, Pg No S29-S31, 2016

[30] Priya, N., Sridhar, J., Sriram, M. "Ecommerce Transaction Security Challenges and Prevention Methods- New Approach” 2016 ,Journal of Chemical and Pharmaceutical Sciences, JCPS Volume 9 Issue 3.page no:S66-S68

[31] Priya, N.,Sridhar,J.,Sriram, M."Vehicular cloud computing security issues and solutions" Journal of Chemical and Pharmaceutical Sciences(JCPS) Volume 9 Issue 2, April - June 2016

[32] Priya, N., Sridhar, J., Sriram, M. "Mobile large data storage security in cloud computing environment-a new approach" JCPS Volume 9 Issue 2. April - June 2016

[33] Anuradha.C, Khanna.V, "Improving network performance and security in WSN using decentralized hypothesis testing "Journal of Chemical and Pharmaceutical Sciences(JCPS) Volume 9 Issue 2, April - June 2016 .

[34] Anuradha.C, Khanna.V, "A novel gsm based control for e-devices" Journal of Chemical and Pharmaceutical Sciences(JCPS) Volume 9 Issue 2, April - June 2016.

[35] Anuradha.C, Khanna.V, "Secured privacy preserving sharing and data integration in mobile web environments " Journal of Chemical and Pharmaceutical Sciences(JCPS) Volume 9 Issue 2, April - June 2016 .

[36] Sundarraj, B., Kaliyamurthie, K.P. Social network analysis for decisive the ultimate classification from the ensemble to boost accuracy rates 2016 International Journal of Pharmacy and Technology

[37] Sundarraj, B., Kaliyamurthie, K.P. A content-based spam filtering approach victimisation artificial neural networks 2016 International Journal of Pharmacy and Technology83.

[38] Sundarraj, B., Kaliyamurthie, K.P. Remote sensing imaging 
for satellite image segmentation 2016 International Journal of Pharmacy and Technology83.

[39] Sivaraman, K., Senthil, M. Intuitive driver proxy control using artificial intelligence 2016 International Journal of Pharmacy and Technology84.

[40] Sivaraman, K., Kaliyamurthie, K.P. Cloud computing in mobile technology 2016 Journal of Chemical and Pharmaceutical Sciences92.

[41] Sivaraman, K., Khanna, V. Implementation of an extension for browser to detect vulnerable elements on web pages and avoid click jacking 2016 Journal of Chemical and Pharmaceutical Sciences92.

\section{AUTHORS PROFILE}

N.Priya, Assistant Professor, Department of Computer Science \& Engineering, Bharath Institute of Higher Education and Research, Chennai, India

Ms. S. Sangeetha, Assistant Professor, Department of Computer Science \& Engineering, Bharath Institute of Higher Education and Research, Chennai, India

Ms. S. Amudha, Assistant Professor, Department of Computer Science \& Engineering, Bharath Institute of Higher Education and Research, Chennai, India 